\title{
Unveiling the Coverage Patterns of Newspapers on the Personal Data Protection Act
}

\author{
Hui Na Chua ${ }^{\mathrm{a}}$, Siew Fan Wong ${ }^{\mathrm{a}}$, Younghoon Chang ${ }^{\mathrm{b}}$, Christian Fernando Libaque-Saenz ${ }^{\mathrm{c}}$ \\ ${ }^{a}$ Dept. of Computing and Information Systems, Sunway University, Malaysia \\ ${ }^{\mathrm{b}}$ Division of Business and Management, BNU-HKBU United International College, China \\ ${ }^{\mathrm{c}}$ Department of Engineering, Universidad del Pacífico, Peru
}

\begin{abstract}
Internet-enabled technology has significantly increased the amount of personal data that are being collected, used, processed and even transferred to third party organizations. To protect the privacy of data owners and the security of these data, the Malaysian government has enforced the Personal Data Protection Act (PDPA) in 2013. Several studies found that Malaysians have low awareness of the PDPA. Prior literature also shows that the framing of news stories by the media has significant influence on public awareness and perception toward a covered topic. In this paper, we investigated how the Malaysian newspapers frame the PDPA news. We extracted a total of 793 news articles between January $1^{\text {st }} 2010$ and July $31^{\text {st }} 2015$ from ten local English newspapers. The results show that newspapers in general have not given the PDPA enough attention considering its potential impact on data privacy and security. Nonetheless, newspapers do publish significantly higher number of PDPA articles after the enforcement period compared to before the enforcement period. The newspapers also mostly position the PDPA news in the Technology section. The results also show that more PDPA news originated from foreign sources compared to local sources or the government. Our findings provide insights into the coverage patterns of local newspapers and the insufficient level of prominence given to the PDPA. The findings have implications for both the government and the newspapers as a media.
\end{abstract}

\section{Keywords:}

Data protection act, privacy, government information dissemination, PDPA, framing, newspaper media 


\section{Introduction}

The increasingly sophisticated Internet-enabled technology has enabled vast amount of personal data being collected, used, processed, stored, and shared digitally online (Caudill \& Murphy, 2000; Conradie \& Choenni, 2014; Libaque-Saenz et al., 2016). These personal data present valuable business opportunities (Fortune 2016). For organizations, they will be able to develop better customer profiles to provide tailored products and services that meet customer needs (Liu \& Arnett, 2002). For government agencies, they will be able to develop better citizen profiles to ensure higher national security and improve civil services (Janssen \& van den Hoven, 2015). The recent big data analytics capabilities and tools further accentuate potential benefits different parties could gauge from having access to large amount of consumer data (Liu \& Arnett, 2002; Libaque-Saenz et al., 2016).

While data accessibility is beneficial, the processes of data collection, storage, and use raise privacy and security concerns. These concerns rise with growing e-commerce and e-government (open government data) activities that increase data flow among different parties and even across different national borders (Dinev \& Hart, 2006; Moores, 2005; Zuiderwijk \& Janssen, 2014; Janssen \& van den Hoven, 2015). To address the concerns, numerous international guidelines as well as countryspecific policies exist to govern appropriate data collection and use. Examples of these guidelines are the US Federal Trade Commission's Fair Information Practices Principles (FIPPs), the European Union's Data Protection Directive and General Data Protection Regulation, and the Organization for Economic Cooperation and Development (OECD)'s guidelines on the Protection of Privacy and Transborder Flows of Personal Data. In Malaysia, its government has enforced the Personal Data Protection Act 2010 (PDPA) in 2013 (PDPA, 2010).

The PDPA is enacted under the contention that the consumers (hence the data owners) are entitled to fair treatment in the way their personal information is collected, stored, and used. The guidelines limit data collection and impose accountability on data collectors, thus controlling the use of personal information (Schwaig et al., 2006; Kassen, 2013). As the data owners, the consumers should be aware of the Act in order to exercise their rights. However, studies indicate that Malaysians' awareness on the Act remains poor. For example, Raus et al. (2014) discover that only $31 \%$ of their respondents were aware of the PDPA.

In addition, the public also lack understanding of privacy issues in general. Hashim et al. (2013) reveal that Malaysian youth's awareness on privacy issues is still at the infancy level which makes them vulnerable to incidents of identity theft." Similarly, Siegel+Gale (2012) found that consumers do not understand how their information are collected and shared with others and how to protect and control their own data. The low level of awareness and interest in privacy related issues is a contributor to the lack of understanding of privacy guidelines in general and the PDPA in particular. A possible solution to this problem is to level the importance of privacy policies and to educate the public on how to control and manage their privacy online (Yanovitzky, 2002).

Prior literature shows that mass media plays an important role to foster the development of and influence public awareness and belief toward an issue (Cohen, 1963; Happer \& Philo, 2013; Yanovitzky, 2002). For example, lead stories, headlines and front page news items tend to have stronger influence on the public's perception on what is important compared to less-emphasized news items (Iyengar \& Simon, 1993; McCombs \& Shaw 1972). Also, through repeated exposure, the public becomes more informed of a frequently covered topic compared to a rarely covered topic (Curran et. al., 2009; McCombs \& Shaw 1972). Therefore, the media is the primary custodian of information on a topic and plays an important role in disseminating information to the public (Happer and Philo, 2013). Newspapers can play a critical role in creating awareness and educating the public on government policies (Leighley, 2003; Yanovitzky, 2002) such as the PDPA. In fact, 
many countries still use the mass media as the trustable source to deliver messages on new regulations and policy guidelines to the people. Despite the crucial role of a newspaper in creating awareness on the PDPA, a critical assessment of how newspapers frame the PDPA news has not been undertaken in the literature. Therefore, the objective of our study is to address this research gap and investigate how PDPA news are disseminated. Our study is guided by the literature on the Theory of Framing.

Another motivation of our research is the lack of similar study among the information privacy literature. The existing literature focuses mostly on individual and organization privacy issues (Smith et al., 2011; Bélanger \& Crossler, 2011) such as how privacy policies influence individual's privacy concern, data control, information risk, privacy status and attitude. These studies are also empirical, survey-based research to develop theories on people's behavior. As the importance of information privacy and protection permeates every part of the society and its enforcement is effective when implemented top-down, it is valuable to extend the research to the national and societal level. Our study focuses on how newspapers in a country carry their role in disseminating information on government's privacy guidelines.

\section{Literature Review}

\subsection{Personal Data Protection Act 2010}

In April 2010, the Malaysian Parliament passed the Personal Data Protection Bill. In November 2013, it enforced the personal data protection law via the Personal Data Protection Act 2010 (PDPA, 2010).The PDPA applies to any person who (1) processes and has control over or authorizes the processing of any personal data for commercial transactions, (2) uses equipment in Malaysia to process personal data other than for the purposes of transit through Malaysia. It requires data users (e.g., a person or a company that processes or controls any personal data) to notify the data subjects (e.g., individuals who is the subject of the personal data) on the purpose of personal data processing and obtain their consent with regards to the purpose.

The PDPA has six core principles. First, the Notice and Choice Principle states that data users shall be providing timely and adequate notice on detailed description of data collected, the data subjects' rights to the data and how to contact the data users with any inquiries and complaints in respect of the personal data. Second, the Disclosure principle establishes that no personal data shall, without the consent of the data subject be disclosed. Third, the Security principle states that a data user shall take practical steps when processing personal data to protect these data from any loss, misuse, modification, unauthorized or accidental access. Forth, the Retention principle declares that the personal data processed for any purpose shall not be kept longer than is necessary for the fulfilment of that purpose. Fifth, the Data Integrity principle sets forth that the data users shall take reasonable steps to ensure that any data collected is accurate, complete, not misleading and kept up-to-date. Sixth, the Access principle establishes that a data subject shall be given access to his/her personal data held by a data user and be able to correct that personal data where the personal data is inaccurate, incomplete, misleading or not up-to-date.

The PDPA authorizes a category of sensitive personal data that requires the explicit consent of the data subjects to be processed. The law further establishes the rights of data subjects such as the right of access to personal data, right to correct personal data, right to withdraw of consent to process personal data, right to prevent processing that is likely to cause damage or distress, and right to prevent processing for purposes of direct marketing. In case of violation, the PDPA imposes 
criminal penalties. If an organization breaches the PDPA, individuals within the management of the business may be jointly and severally liable for non-compliance.

\subsection{Media's Role in Disseminating Policy Information}

The development media theory seeks to explain the normative behavior of the media in countries that are classified as "developing countries" or "third world countries". One of the fundamental principles of the theory is that "the media must accept and conduct positive development tasks in line with national established policy" (McQuail, 1994) "without prejudice to their traditional functions of (disseminating) information, education and entertainment" (Folarin, 1998). Since Malaysia is a developing country, the local media, should play an active role in delivering news on government policies, such as that of the PDPA. Also, since Putrajaya represents the Malaysian government offices, rationally, it should be regarded as the most credible and genuine source of policy news. Previous literature has found a correlation between the impact of media on policy and the source of the news. Reliable and respected news sources have more impact compared to those marginal and questionable news sources (Bartels, 1996).

Though by no means media is the only source of policy agenda, existing work indicates that the media can play an important role. Previous studies (e.g., Baumgartner \& Jones, 1993; Flickinger, 1983; Kingdon, 1984; Mayer, 1991; Pritchard, 1986) point out that while the media may not decide the nature of policy change, it can certainly drive attention towards certain policy domains. In investigating the role of media in drawing public attention on particular issues, McCombs and Shaw (1972) found that the media can effectively underscore public agenda by constantly and remarkably featuring certain issues in their news coverage.

In spite of its importance, there are issues related to the media's role in influencing the policy process. Examples of these issues are biases in the coverage, the use of active conflict frames to increase the readers' interest, the lack of sufficient contexts provided for the readers to understand contentious policy options, and the reporters lacking of technical proficiency in the matters written. All these issues may affect how policies are being conveyed to the public (Entman, 2004;

Farnsworth \& Lichter, 2006, 2011; Larson, 2001; Boykoff, 2005; Mooney, 2004; Iyengar \& Kinder, 1987).

\subsection{The Role of Newspapers in Agenda Setting and Framing}

The newspapers, as a media, plays an important role in disseminating information to the public on what is happening in the world, especially in areas which the readers do not know about and have no direct knowledge or experience (Happer \& Philo, 2013). It has three basic functions: agendasetting, priming and framing (Peterson, 2014).

Agenda-setting is where the media's focus on certain topics leads the public to perceive those matters as more significant. The media decides where (through positioning or categorization) within the newspaper the stories of the day should appear (Baran \& Davis, 2009). The space dedicated to a story, the size and the number of photographs featured with the story, the headlines given, the length of the story, and the number of repetitions are all regarded as indications of its level of importance (Eveland et al., 2004; Scheufele \& Tewksbury, 2007; Tewksbury \& Althaus, 2000). The headline, for example, provides the main idea of an article to catch the readers' attention (Ecker et al., 2014). Important stories often appear on the front page and have larger headlines while less important ones tend to appear in subsequent pages with smaller headlines (De Vreese, 2005). When news are positioned at the forefront of a newspaper, it becomes more effective (Iyengar \& Simon, 1993; McCombs \& Shaw, 1972). In priming and framing, newspapers' attention to some issues and 
not others may alter how the public perceive, understand and evaluate an issue (Iyengar \& Simon, 1993; McCombs, 2004; McQuail 1994; Scheufele \& Tewksbury, 2007).

Since the literature found that the determinants of effective information dissemination are repetitive information exposed, positioning of news content in headlines and credible source of news, our study checked for the presence of these determinants in the dissemination of PDPA news by local newspapers.

\subsection{Existing Studies on Different News'Sections and Their Characteristics}

Alongside with the examination of media content, scholars have also addressed the issues related to how different kinds of news are classified by journalists (Limor \& Mann, 1997; Smith, 1985; Lehman-Wilzig \& Seletzky, 2010; Tuchman, 1973; Whetmore, 1989; Patterson, 2000) and the effects of the classification on the perception of audiences and the amount of political facts they obtained (Patterson, 2000; Baum, 2003; Grabe et al., 2001; Prior, 2003). Lehman-Wilzig and Seletzky (2010) give an extensive classification of news which consists of 'General', 'Soft' and 'Hard' categories. The concise characteristics of these categories and their perceived importance are as follows:

- 'General' news

- Categories: Business, economics, finance, social/cultural stories.

- Important news that is relevant or influential. It is meant only for a specific group, and not for the society in general. The news needs not be reported immediately.

- 'Soft' news

- Categories: Arts, leisure, women, tourism, supplement, women, 'light' news, e.g., gossip, celebrity stories.

- There is no intrinsic importance to the news, but rather it draws public interest. The news needs not be reported immediately.

- 'Hard' news

- Categories: Main news section. The stories are of great significant for most of the public especially those news related to the nation (society welfare and politics) and environment that have ramification on the public and the world.

- Important news that need to be reported as soon as possible.

The news classification demonstrates different levels of importance and urgency. The PDPA is an enforced government policy that influences most of the public, and impacts all individuals whose personal data is being collected and used by companies. The public needs to be informed immediately about the PDPA and its enforcement. Therefore, the reporting of the PDPA news can be considered as 'Hard' news that need to be reported as soon as possible. It should also appear in the main news section.

\subsection{Knowledge Acquisition through Word Exposure}

The Linguistic field contends that extensive reading could help to learn new words and deepen the knowledge of already known words (Schmitt \& McCarthy, 1997). The act of reading provides readers an opportunity to encounter and process unfamiliar words in natural context (Horst et al., 1998). This is known as Incidental vocabulary acquisition (IVA). In IVA, readers focus their attention on words in various exercises and activities. One of the key factors that influence IVA is word exposure frequency. Exposure frequency influences word gains by increasing the possibility of a word to be noticed and processed by the reader, and by strengthening the association between 
lexical stimuli (target words) and mental responses (cognitive processing). Hence, a word that has high frequency is likely to receive more attention from readers (Zhu, 2015). Moreover, readers are able to learn the meaning of the words if the words appear repeatedly in informative contexts (Web, 2008).

Studies show a correlation between word repetition and gains in knowledge acquisition. When words that are likely to be new to the readers are repeated eight or more times, sizable and consistent learning is achieved (Horst et al., 1998; Webbs, 2007; Rott, 1999; Saragi et al., 1978; Waring \& Takaki, 2003). In our study, we used 'degree of exposure' of target words to indicate the importance of targeted words occurrence and coverage across wide range texts or documents. Specifically, we analyzed the frequency at which certain words occurred and the most emphasized words in PDPA news

\subsection{Knowledge Acquisition and Media Visibility}

Constant repetition of a news or story leads readers to give it greater importance (Baran \& Davis, 2009). The literature also suggests a significant statistical relationship between extended media visibility (six months compared to one month) and public knowledge. Visibility scores in the long period (in the 6 months preceding to the study survey) are good predictors compared to short period (Curran et. al. 2009).

Exposure to one news story presented at a single time may not necessarily lead to learning of any significance. Important events and issues often receive extensive coverage over time. When the media presents similar stories over a period of time, they give the readers the opportunity to mentally rehearse the information which allows the individuals to retain the information (Tewksbury et. al., 2001). People who are exposed to a lower volume of coverage are less able to evaluate a subject topic (Hayes \& Lawless, 2015).

Existing studies have presented the evidence that shows constant repetition and extended visibility of a news significantly contribute to public knowledge and information retention. Therefore, if PDPA news is given sufficient visibility, it will give the public adequate time to absorb and learn about the policy.

Upon the backdrop of our literature review and the motivation to uncover how local newspapers frame the PDPA (2010) news, we post the following research questions:

(1) What is the visibility level of the PDPA news?

(2) How much do PDPA-related keywords appear on story headlines?

(3) In which newspaper section does PDPA news appear?

(4) What is the source of the PDPA news?

(5) What keyword is most emphasized in PDPA news?

\section{Methods}

We adopted the KDT (Knowledge Discovery in Text) technique to process the data. KDT is a generic text mining method that contains three phases: data collection, document pre-processing, and data analysis (Fan et al., 2005). 


\subsection{Data collection}

The data collection phase entails first determining what data will be used in the study. We collected data from online news articles because archived news is more complete in digital format. According to the Bureau of Circulation, between January 2016 to June 2016, English newspapers occupied $35 \%$ of the total local newspapers (including all paid, free and controlled newspapers in Malay, English, Chinese and Tamil languages) circulation in Malaysia. This coverage suggests that the local English newspapers can be considered as representative of newspaper circulation.

Geographically, Malaysia consists of the western (Peninsular) and the eastern (Sarawak and Sabah) regions. The English newspapers' circulation is 32\% (Peninsular), 35\% (Sarawak) and 38\% (Sabah) respectively (Audit Bureau of Circulations Malaysia, 2016).

Eleven Malaysian English newspapers were initially selected because of their availability in digital format for data collection: The Star, New Straits Times, The Malaysian Insider, Borneo Post, Free Malaysia Today, The Sun Daily, FZ, New Sarawak Tribute, The Edge Markets, Malaysia Kini and New Sabah Times. We excluded the newspapers that only have digital format (i.e., Malaysia Kini, The Malaysian Insider, Free Malaysia Today and FZ) and without publicly available circulation rate (i.e., New Sarawak Tribune). The selected newspapers represent $61 \%$ of the overall circulated English newspapers coverage across the whole Malaysia (Audit Bureau of Circulation). In addition, the Star newspaper announced that their readers consists of Chinese (43\%), Malay (28\%), Indian and other foreigners (29\%). This shows that English newspapers are read by the majority of the ethnic groups in Malaysia (Thestar, 2015).

Alongside with the sampling analysis, we further considered the natures and features of the selected newspapers as in Table 1:

Table 1.

Nature and feature of Malaysian English newspapers.

\begin{tabular}{|c|c|c|}
\hline Newspaper & Availability & National reach \\
\hline Borneo Post & $\begin{array}{l}\text { Print copies only available in } \\
\text { Sarawak and Sabah. } \\
\text { Covers wide spectrum of subjects. }\end{array}$ & $\begin{array}{l}\text { *Contributes } 34 \% \text { and } 45 \% \text { of } \\
\text { English newspapers' circulation in } \\
\text { Sabah and Sarawak respectively. The } \\
\text { highest circulated English daily } \\
\text { newspaper in East Malaysia. }\end{array}$ \\
\hline Free Malaysia Today & $\begin{array}{l}\text { Digital format only. } \\
\text { Covers wide spectrum of subjects. }\end{array}$ & $\begin{array}{l}\text { The news portal claimed it has an } \\
\text { average of } 300,000 \text { daily visitors. }\end{array}$ \\
\hline Malaysia Kini & $\begin{array}{l}\text { Digital format only. } \\
\text { Its news coverage concentrates } \\
\text { mainly on local events, with a strong } \\
\text { emphasis on items related to } \\
\text { Malaysian politics. }\end{array}$ & $\begin{array}{l}\text { Compete.com estimated over } 10,000 \\
\text { unique visitors visited the online } \\
\text { news site in May } 2009 .\end{array}$ \\
\hline New Sabah Times & $\begin{array}{l}\text { Print copy only available in Sabah. } \\
\text { Covers wide spectrum of subjects. }\end{array}$ & $\begin{array}{l}\text { *Contributes } 24 \% \text { of English } \\
\text { newspapers in Sabah. }\end{array}$ \\
\hline New Sarawak Tribune & $\begin{array}{l}\text { Print copy only available in Sarawak. } \\
\text { Covers wide spectrum of subjects. }\end{array}$ & Circulation figure is not available. \\
\hline The Edge & Available in all regions. & *Contributes $2 \%$ of all English \\
\hline
\end{tabular}


Its news coverage is business and investment oriented.

The Malaysian Insider Digital format only.

Covers multiple sections but political news and commentaries dominated its coverage.

Only available in Peninsular.

Covers wide spectrum of subjects.

Digital format only.

Covers wide spectrum of subjects.

The Star

Available in all regions.

Covers wide spectrum of subjects.

New Strait Times

Available in all regions.

Covers wide spectrum of subjects. newspapers.

Compete.com estimated that almost 19,000 unique visitors visited the online news in April 2009.

Blocked by the country's Internet regulatory body in February 2016. Ceased publication in March 2016.

*Contributes $29 \%$ and is the highest circulated English newspapers in the Peninsular.

Visitors' figure is not available.

*Contributes $22 \%$ of the overall

English circulated newspapers.

* Contributes $5 \%$ of the overall circulated English newspapers.

*Source: Audit Bureau of Circulations, Malaysia - Jan to Jun 2015 Bureau of Circulation

For the data collection, we included all news articles between January $1^{\text {st }} 2010$ and July $31^{\text {st }} 2015$. This period coincides with the time when the PDPA bill was passed in April 2010 and its enforcement starting November 2013. To identify relevant articles; we filtered the news content using keywords "personal data", "data protection", and "PDPA". This process yielded a total of 835 relevant articles (see Table 2). However, we have to exclude New Strait Times from our sample because it only has digital archived copies starting from January 2014, which does not coincide with the two important events of the PDPA bill passing and enforcement. Our final samples size is a total of 793 articles from ten newspapers.

For each relevant article, the information collected include the title, the content, the publication date, the category or section at which the news is published in the newspaper (such as nation, world, business, and technology), and the cited source (such as Washington, Kuala Lumpur, and London). All data were stored in an Oracle system database. Advanced SQL (Structured Query Language) was used to retrieve the data and perform keywords search.

Table 2.

Number of articles from each newspaper.

\begin{tabular}{llll}
\hline Newspaper & $\begin{array}{l}\text { The first time when } \\
\text { relevant articles } \\
\text { appeared }\end{array}$ & $\begin{array}{l}\text { The latest time when } \\
\text { relevant articles } \\
\text { appeared }\end{array}$ & $\begin{array}{l}\text { Number of articles } \\
\text { included }\end{array}$ \\
\hline Borneo Post Online & APR-2010 & JUL-2015 & 97 \\
Free Malaysia Today & APR-2011 & JUL-2015 & 93 \\
Malaysia Kini & JAN-2010 & JUL-2015 & 11 \\
New Sabah Times & MAY-2010 & MAY-2015 & 10
\end{tabular}




\begin{tabular}{llll} 
New Sarawak Tribune & MAR-2013 & JAN-2015 & 23 \\
The Edge Markets & JAN-2010 & JUN-2015 & 12 \\
The Malaysian Insider & APR-2010 & JUL-2015 & 19 \\
The Sun Daily & JAN-2010 & JUL-2015 & 80 \\
FZ & NOV-2012 & JUN-2015 & 60 \\
The Star & JAN-2010 & JUL-2015 & 209 \\
New Strait Times* & JUN-2014 & JUL-2015 & 42 \\
\hline
\end{tabular}

*excluded from this study

\subsection{Document Pre-processing}

After the data collection, we performed data pre-processing where we cleansed and transformed the data. We eliminated "stopword" (i.e., frequently used terms such as conjunctions and prepositions). We also applied stemming algorithms where we converted all terms into their canonic form in order to have wider catch of the word families. For instance, verb in imperative form 'protecting' becomes 'protect'.

To further group the articles, we added two types of tags. The first tag is the category of the articles to indicate the section of a newspaper where a particular article appears. We used six category labels: Nation (includes local and national news), World, Business, Technology, Leisure (includes lifestyle, sports, entertainment, health, features and community) and Opinion (includes viewpoints, columnists, letters and side views). While some newspapers used more category labels, the six that we adopted here were the most commonly used categories in all the sample newspapers. In order to analyze the characteristics and the importance of each category, we mapped them into applicable news types ('General', 'Soft', 'Hard'):

- 'Hard' news: Nation, World (both can be classified as 'hard' news if they have ramification on the national public)

- 'Soft' news: Leisure

- 'General' news: Business, Technology, Opinion, Nation, World (Nation and World can be considered as 'general' news if they do not have ramification on the notional public)

The second tag is the cited sources to indicate the origin of the news. We used three types of cited sources: foreign (sources from foreign countries), local (sources from within Malaysia) and Putrajaya (sources from the Malaysian government offices).

\subsection{Data analysis}

To analyze the data, we performed term occurrence and frequency count. Following the literature in information theory that defines the importance of a term in a document set (Santos et al., 2008), we used TF-IDF (Term Frequency - Invert Document Frequency) index to perform the calculation. RapidMiner text mining tool was used for this task. The output produced by RapidMiner contains a list of terms and their frequency.

From the occurrences of terms generated, we further analyzed the degree of exposure, which is the ratio between the total number of occurrences of a term and the number of documents in which the term appears. For example, a degree exposure of 1 indicates that a term appears only once in each 
document, whereas 2 means that on average the term appears twice in each document. Prior literature has revealed the correlation between word repetition and gains in knowledge acquisition in the context of first and second language vocabulary learning, though with different suggestions of how many encounters are necessary for acquisition to occur (Webbs, 2007). Rott (1999) reports that 6 may be enough, Horst et al. (1998) suggest 8, Saragi et al. (1978) suggest 10, and Waring and Takaki (2003) argues that it may take more than 20 encounters.

\section{Results}

\subsection{Visibility level of the PDPA news}

According to Framing Theory (Curren et al. 2009), exposure to one news story presented at a single time may not necessarily lead to learning of any significance. Instead, the visibility score of a longer period (i.e., six months) is a better predictor of information retention compared to the visibility score of a shorter period (i.e., one month) (Curren et al. 2009). Since the literature has not specified the threshold that would qualify as "sufficient visibility", we took a conservative step by examining if the PDPA-related news are covered at least once a month within any continuous six-month period.

Fig.1. shows the occurrence of PDPA-related articles over time. The trend was not uniform across newspapers. For example, Borneo Post had the longest period (26 months) with at least one PDPArelated article per month. The occurrence of these articles was higher after the PDPA enforcement than before it. Free Malaysia Today had a similar trend in the longer period with at least one PDPArelated article after the PDPA enforcement than before it.

In the case of Malaysia Kini, New Sabah Times, and The Edge Markets, small effort was made to diffuse PDPA-related issues. Actually, these three newspapers addressed the PDPA topics only a few times within the period under study. On the other hand, New Sarawak Tribune published articles related to the PDPA around its enforcement period (ten continuous months: six before and four after the enforcement), while it barely addressed these topics at any other time. A similar trend was shown by The Sun Daily and FZ. However, the former has addressed the PDPA more frequently and longer than the latter.

Malaysian Insider was most consistent in addressing the PDPA topics over time both before and after PDPA enforcement. The Star placed more emphasis on the PDPA topics after its enforcement than before it. In any case, there was no significant difference in number of months with at least one PDPA-headline before and after the PDPA enforcement. The Sun Daily and The Star had the highest number of months (10 months) with at least one PDPA-headline. 


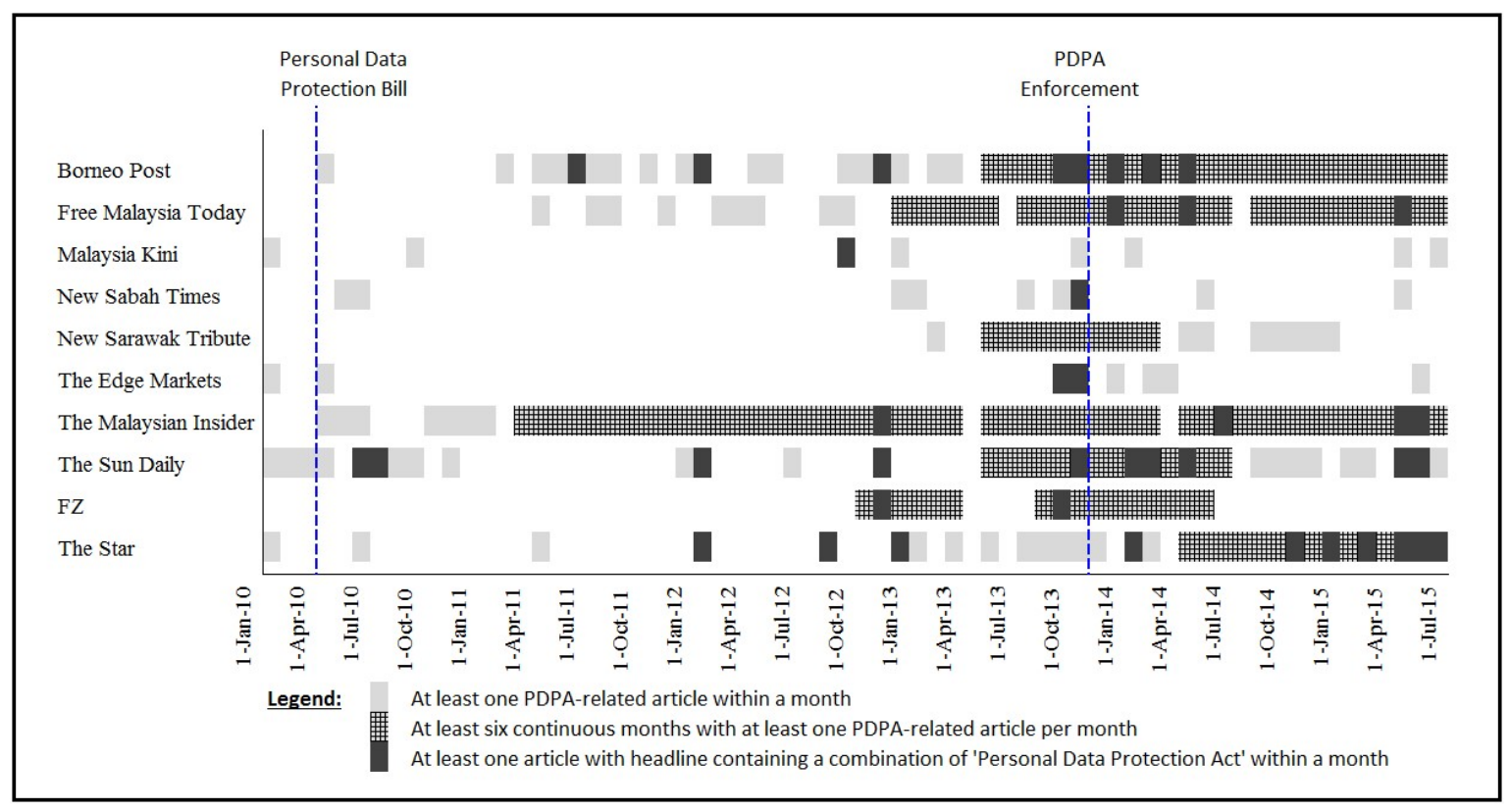

Fig. 1. Occurrence of PDPA-related articles over time

\subsection{Appearance of PDPA Keywords on News Headlines}

Fig. 2. shows the number of headlines with and without the combination of the phrase 'Personal Data Protection Act'. Following Curren et al. (2009) which suggests that good visibility occurs in the long terms rather than in short terms, we compared the number of PDPA-headlines six months before and after the PDPA was enforced. The number of PDPA-headlines six months before the enforcement was 3 (out of a total of 71) while the number of PDPA-headlines six months after the enforcement was 13 (out of a total of 128). We conducted chi-square tests to examine the distribution of the number of PDPA-headlines between these two periods. When the chi-square assumptions were not met (i.e., when one cell has an expected count of less than one or more than $20 \%$ of the cells have an expected count of less than five), we performed Fisher's exact test. We found that after the PDPA enforcement, the number of PDPA-headlines was significantly higher than the number of PDPA-headlines before the enforcement $\left(\mathrm{X}_{1}{ }_{1}=6.250, p\right.$-value $\left.=0.012\right)$. However, when comparing the proportion of the number of PDPA-headlines to the number of total headlines in these two six-month periods, the difference became non-significant $\left(\mathrm{p}_{\text {before }}=0.042, \mathrm{p}_{\text {after }}=0.102\right.$, $\mathrm{Z}=1.474, p$-value $=0.140$ ), albeit the proportion after the PDPA enforcement was almost thrice as large as the proportion before it. Overall, the very small number of news with the PDPA-headlines implies that not much emphasis was given to the PDPA. 


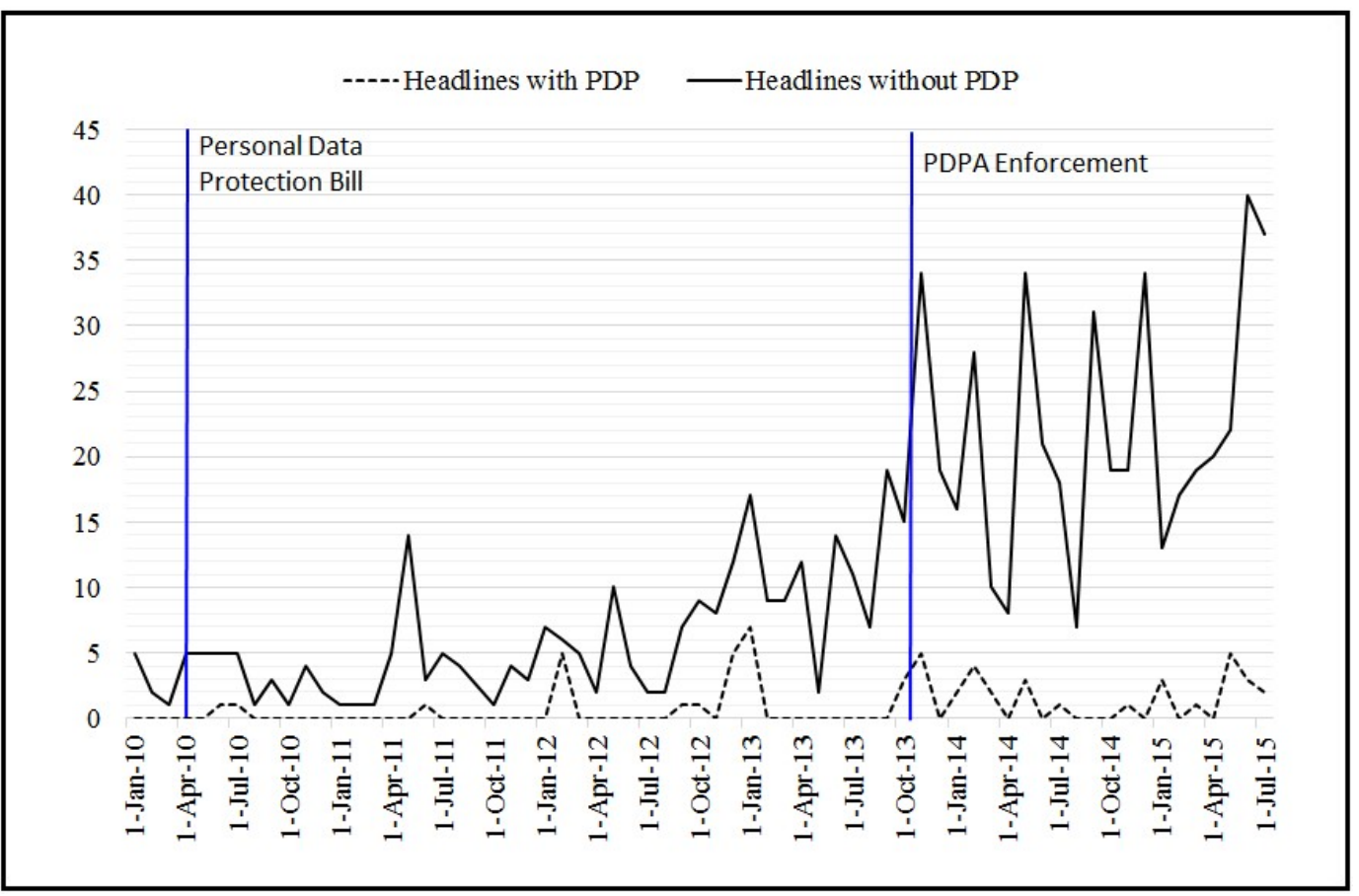

Fig. 2.Number of headlines with and without PDPA over time

\subsection{Positioning of the PDPA News in Different Newspaper Sections}

Furthermore, Table 3 shows the number of PDPA-related articles across categories in each newspaper. We also conducted chi-square tests to examine the distribution of PDPA-related news across categories. The tests revealed there were significant differences across the six categories $\left(\mathrm{X}_{5}{ }_{5}=235.361\right.$, $\mathrm{p}$-value $\left.=0.000\right)$. Accordingly, we performed multiple pairwise comparisons, as shown in Table 2. Technology was the category with the highest number of news related to the PDPA with 261 articles, followed by World with 160 articles. The categories Nation and Business had 148 and 123 articles respectively while the categories Opinion and Leisure had the lowest number of articles with 56 and 45 news each respectively. The number of PDPA news in the Technology section was significantly higher from the number of PDPA news in the other five categories.

\section{Table 3}

PDPA-related news across categories in each newspaper.

\begin{tabular}{|c|c|c|c|c|c|c|c|c|c|c|c|c|c|}
\hline \multirow{2}{*}{$\frac{\text { Newspaper / Category }}{\text { Borneo Post }}$} & \multicolumn{2}{|c|}{ Nation } & \multicolumn{2}{|c|}{ Opinion } & \multicolumn{2}{|c|}{ Technology } & \multicolumn{2}{|c|}{ Leisure } & \multicolumn{2}{|c|}{ Business } & \multicolumn{2}{|c|}{ World } & \multirow{2}{*}{$\begin{array}{r}\text { Total } \\
97\end{array}$} \\
\hline & 39 & $40 \%$ & 1 & $1 \%$ & 16 & $16 \%$ & 1 & $1 \%$ & 21 & $22 \%$ & 19 & $20 \%$ & \\
\hline Free Malaysia Today & 20 & $22 \%$ & 7 & $8 \%$ & 0 & $0 \%$ & 14 & $15 \%$ & 18 & $19 \%$ & 34 & $37 \%$ & 93 \\
\hline Malaysia Kini & 6 & $55 \%$ & 5 & $45 \%$ & 0 & $0 \%$ & 0 & $0 \%$ & 0 & $0 \%$ & 0 & $0 \%$ & 11 \\
\hline New Sabah Times & 8 & $80 \%$ & 0 & $0 \%$ & 0 & $0 \%$ & 1 & $10 \%$ & 0 & $0 \%$ & 1 & $10 \%$ & 10 \\
\hline
\end{tabular}




\begin{tabular}{lrrrrrrrrrrrrr} 
New Sarawak Tribute & 5 & $22 \%$ & 1 & $4 \%$ & 11 & $48 \%$ & 0 & $0 \%$ & 1 & $4 \%$ & 5 & $22 \%$ & 23 \\
The Edge Markets & 1 & $8 \%$ & 0 & $0 \%$ & 2 & $17 \%$ & 1 & $8 \%$ & 7 & $58 \%$ & 1 & $8 \%$ & 12 \\
The Malaysian Insider & 9 & $5 \%$ & 28 & $14 \%$ & 71 & $36 \%$ & 10 & $5 \%$ & 36 & $18 \%$ & 44 & $22 \%$ & 198 \\
The Sun Daily & 14 & $18 \%$ & 7 & $9 \%$ & 22 & $28 \%$ & 0 & $0 \%$ & 18 & $23 \%$ & 19 & $24 \%$ & 80 \\
FZ & 9 & $15 \%$ & 1 & $2 \%$ & 36 & $60 \%$ & 3 & $5 \%$ & 4 & $7 \%$ & 7 & $12 \%$ & 60 \\
The Star & 37 & $18 \%$ & 6 & $3 \%$ & 103 & $49 \%$ & 15 & $7 \%$ & 18 & $9 \%$ & 30 & $14 \%$ & 209 \\
\hline Total & 148 & $19 \%$ & 56 & $7 \%$ & 261 & $33 \%$ & 45 & $6 \%$ & 123 & $16 \%$ & 160 & $20 \%$ & 793 \\
\hline
\end{tabular}

\section{Table 4}

Multiple pairwise comparisons among categories in newspapers.

\begin{tabular}{llllll}
\hline Category & Nation & Opinion & Technology & Leisure & Business \\
\hline Opinion & $\mathrm{X}(1)=41.490^{* *}$ & & & & \\
Technology & $\mathrm{X}(1)=31.220^{* *}$ & $\mathrm{X}(1)=132.571^{* *}$ & & & \\
Leisure & $\mathrm{X}(1)=54.969^{* *}$ & $\mathrm{X}(1)=1.198$ & $\mathrm{X}(1)=152.471^{* *}$ & & \\
Business & $\mathrm{X}(1)=2.306$ & $\mathrm{X}(1)=25.078^{* *}$ & $\mathrm{X}(1)=49.594^{* *}$ & $\mathrm{X}(1)=36.214^{* *}$ & \\
World & $\mathrm{X}(1)=0.468$ & $\mathrm{X}(1)=50.074^{* *}$ & $\mathrm{X}(1)=24.230^{* *}$ & $\mathrm{X}(1)=64.512^{* *}$ & $\mathrm{X}(1)=4.837^{*}$ \\
\hline * $<0.05 ; * * \mathrm{p}<0.001$ & & & &
\end{tabular}

By further comparing the newspapers, we found that The Star and The Malaysian Insider had the highest number of articles related to the PDPA with 209 and 198 news respectively. Borneo Post followed in the third place with 97 articles and Free Malaysia Today has 93 articles. Malaysia Kini, News Sabah Times, and The Edge Markets all had less than 15 articles, which were very small compared that of The Star and The Malaysian Insider. For each category, the newspapers with the highest number of articles related to the PDPA areas follows:

- Nation: Borneo Post (39) and The Star (37) - no significant difference between them, $\mathrm{X}^{2}{ }_{1}=0.053, p$-value $=0.819$.

- Opinion: The Malaysian Insider (28) followed by Free Malaysia Today (7) - there was a significant difference between them, $\mathrm{X}_{1}{ }_{1}=12.600, p$-value $=0.000$.

- Technology: The Star (103) followed by The Malaysian Insider (71) - there was a significant difference between them, $\mathrm{X}_{1}{ }_{1}=5.885, p$-value $=0.015$.

- Leisure: The Star (15), Free Malaysia Today (14), and The Malaysian Insider (10) - no significant difference among them, $\mathrm{X}_{2}^{2}=1.077, p$-value $=0.584$.

- Business: The Malaysian Insider (36) followed by Borneo Post (21) - there was a significant difference between them, $\mathrm{X}^{2}=3.947, p$-value $=0.047$.

- World: The Malaysian Insider (44), Free Malaysia Today (34), and The Star (30) - no significant difference among them, $\mathrm{X}_{2}{ }_{2}=2.889, p$-value $=0.236$. 


\subsection{Sources of the PDPA news}

We compared the number of PDPA-related articles across three sources - government offices (i.e., Putrajaya), local sources other than the government, and foreign news agencies. Table 5 shows the number of PDPA-related articles for each source type along with their corresponding percentage. We conducted chi-squared tests to examine the distribution of PDPA-related news across source types. The tests revealed there were significant differences across the three source types $\left(\mathrm{X}_{2}{ }_{2}=415.433, p\right.$-value $\left.=0.000\right)$. Accordingly, we performed multiple pairwise comparisons. Foreign sources had the highest number of news related to PDPA with 480 articles, followed by Local (Others) with 298 articles. There were significant differences between the number of articles of these two source types $\left(\mathrm{X}_{1}{ }_{1}=42.576, p\right.$-value $\left.=0.000\right)$. On the other hand, the government office (Putrajaya) had issued the lowest number of articles-15 articles, which was significantly lower than the number of articles of Local (Other than Putrajaya) source, $\mathrm{X}^{2}=255.875, p$-value $=0.000$.

\section{Table 5}

PDPA-related news across source types.

\begin{tabular}{lcccccc}
\hline \multirow{2}{*}{ Newspaper / Source } & Putrajaya* & \multicolumn{3}{c}{ Local (Other than } \\
Putrajaya) & \multicolumn{2}{c}{ Foreign } \\
\hline Borneo Post & 2 & $2 \%$ & 54 & $56 \%$ & 41 & $42 \%$ \\
Free Malaysia Today & 0 & $0 \%$ & 29 & $31 \%$ & 64 & $69 \%$ \\
Malaysia Kini & 0 & $0 \%$ & 11 & $100 \%$ & 0 & $0 \%$ \\
New Sabah Times & 1 & $10 \%$ & 7 & $70 \%$ & 2 & $20 \%$ \\
New Sarawak Tribute & 3 & $13 \%$ & 11 & $48 \%$ & 9 & $39 \%$ \\
The Edge Markets & 1 & $8 \%$ & 8 & $67 \%$ & 3 & $25 \%$ \\
The Malaysian Insider & 0 & $0 \%$ & 40 & $20 \%$ & 158 & $80 \%$ \\
The Sun Daily & 2 & $3 \%$ & 39 & $49 \%$ & 39 & $49 \%$ \\
FZ & 0 & $0 \%$ & 13 & $22 \%$ & 47 & $78 \%$ \\
The Star & 6 & $3 \%$ & 86 & $41 \%$ & 117 & $56 \%$ \\
\hline Total & 15 & $2 \%$ & 298 & $38 \%$ & 480 & $61 \%$ \\
\hline
\end{tabular}

*Putrajaya refers to the government office

When comparing the number of PDPA-related articles per newspaper across source types, we obtained the following results:

- Local (Putrajaya): There were no significant differences in number of PDPA-related articles across the ten newspapers (Fisher's exact $p$-value $=0.579$ ).

- Local (Other than Putrajaya): The Star had the highest number of PDPA-related articles (86) followed by Borneo Post (54). There was a significant difference between them, $\mathrm{X}^{2}{ }_{1}=7.314$, $p$-value $=0.007$. 
- Foreign: The Malaysian Insider had the highest number of PDPA-related articles (158) followed by The Star (117). There was a significant difference between them, $\mathrm{X}^{2}=6.113, p$ value $=0.013$.

In addition, Fig. 3. shows the number of PDPA-related articles across the time period of study for all three source types. We can observe that the Putrajaya government was not engaged with the diffusion of the Personal Protection Bill until the PDPA was enforced, almost 4 years later. After this enforcement, the government office made a few attempts to diffuse the information. In the case of Local (other than Putrajaya) and Foreign sources, both of them presented similar patterns showing a low activity before the PDPA was enforced and an increase in the activity after the enforcement.

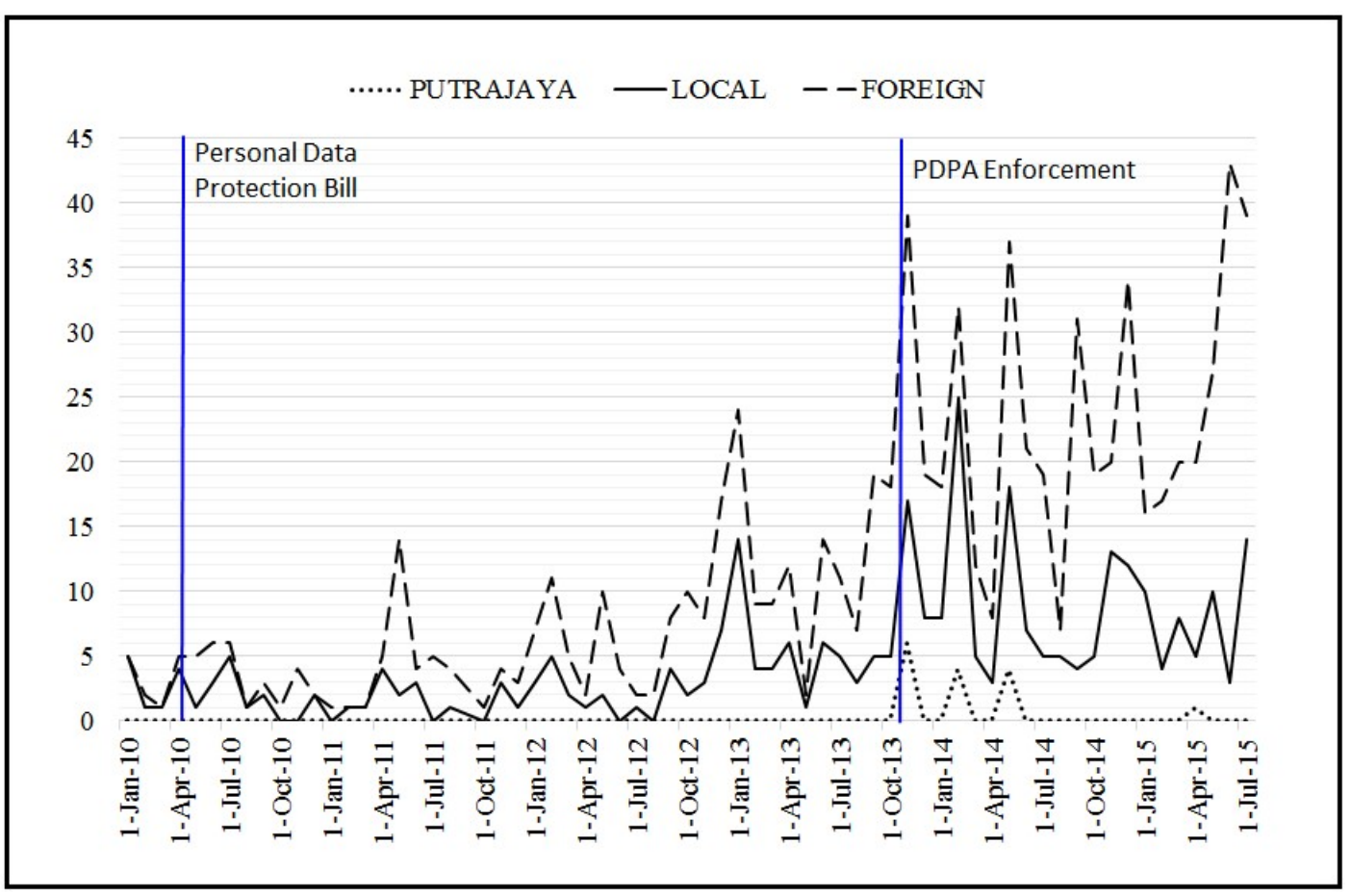

Fig. 3.Number of PDPA-related articles per source type over time

We compared the number of articles in a six-month period (following Curren et al., 2009) before the PDPA was enforced with the number of articles in a six-month period after the enforcement. In addition, we conducted similar comparison using a one-year period before and after the PDPA enforcement to analyze the differences. Table 6 presents the number of articles and the results of the comparisons.

\section{Table 6}


PDPA-related news trend before and after the PDPA enforcement.

\begin{tabular}{|c|c|c|c|c|c|c|}
\hline \multirow[b]{2}{*}{ Source } & \multicolumn{2}{|c|}{ Number of articles } & \multirow{2}{*}{$\begin{array}{l}\text { Sig. Difference } \\
\text { (Chi-squared } \\
\text { test) }\end{array}$} & \multicolumn{2}{|c|}{ Number of articles } & \multirow{2}{*}{$\begin{array}{l}\text { Sig. Difference } \\
\text { (Chi-squared } \\
\text { test) }\end{array}$} \\
\hline & $\begin{array}{l}\text { 6-months } \\
\text { before }\end{array}$ & $\begin{array}{l}\text { 6-months } \\
\text { after }\end{array}$ & & $\begin{array}{l}1 \text {-year } \\
\text { before }\end{array}$ & 1-year after & \\
\hline Putrajaya & 0 & 10 & $\mathrm{X}^{2}{ }_{1}=10.000^{*}$ & 0 & 14 & $\mathrm{X}^{2}{ }_{1}=14.000 * *$ \\
\hline Local & 25 & 56 & $\mathrm{X}_{1}^{2}=11.864^{*}$ & 63 & 96 & $\mathrm{X}_{1}^{2}=6.849^{*}$ \\
\hline Foreign & 46 & 62 & $\mathrm{X}^{2}{ }_{1}=2.370$ & 87 & 152 & $\mathrm{X}^{2}{ }_{1}=16.678 * *$ \\
\hline Total & 71 & 128 & $\mathrm{X}^{2}{ }_{1}=16.237^{* *}$ & 150 & 262 & $\mathrm{X}^{2}{ }_{1}=30.447 * *$ \\
\hline
\end{tabular}

The results of the comparison support evidence from Figure 3 as follows. First, there was no activity from the government office (Putrajaya) on the diffusion of the PDPA information until its enforcement in November 2013. The number of articles related to the PDPA after the enforcement was significantly higher than the number of articles before it. Second, there were some attempts by local news to diffuse the PDPA information before its enforcement. After the enforcement, the press stepped up their effort substantially as evidenced by the significance level between the number of articles before and after the enforcement.

Third, in the case of foreign news, the number of articles in the six-month period after the PDPA enforcement was higher than the number of articles in the six-month period before it, albeit this difference was not significant. However, by further analyzing the number of articles in a period of one year before and after the enforcement, the difference became significant. Indeed, the total number of articles after the PDPA enforcement was significantly higher than the total number of articles before it.

\subsection{Important keywords in PDPA news}

We used the degree of exposure to identify important keywords in PDPA news and to estimate if these terms are effectively repeated across the three news sources of Putrajaya, Local (other than Putrajaya) and Foreign (see Table7). For similar words that appear across all three sources, the degree of exposure was higher for the Putrajaya source than for other sources. For example, the degree of exposure of the word 'data' was higher for Putrajaya source than it is for local or foreign sources. These differences were significant: $\mathrm{X}^{2}{ }_{1}=5.762(p$-value $=0.016)$ for local source and $\mathrm{X}^{2}{ }_{1}=7.200$ ( $p$-value $\left.=0.007\right)$ for foreign source respectively. Similar results were found with other words, such as 'protect,' 'user,' and 'inform,' albeit these differences were not significant. 
Table 7

Degree of word exposure (e) across sources.*

\begin{tabular}{|c|c|c|c|c|c|c|c|c|c|}
\hline $\begin{array}{l}\text { All Samples } \\
\text { (793 articles) }\end{array}$ & & $\begin{array}{l}\text { Foreign } \\
\text { (480 artic }\end{array}$ & & $\begin{array}{l}\text { Local } \\
\text { (298 articles) }\end{array}$ & & $\begin{array}{l}\text { Putrajaya } \\
\text { (15 articles) }\end{array}$ & & & \\
\hline Words & e & Words & e & Words & e & Words & e & Words & e \\
\hline data & 4.63 & data & 4.05 & data & 5.00 & Data & 15.87 & purpose & 1.40 \\
\hline person & 2.44 & user & 2.08 & person & 3.35 & Person & 8.20 & shabery said & 1.40 \\
\hline inform & 2.00 & secur & 1.96 & personal_data & 2.23 & personal_data & 7.73 & $\mathrm{rm}$ & 1.33 \\
\hline compani & 1.89 & compani & 1.95 & inform & 2.17 & protect & 4.80 & bank & 1.27 \\
\hline user & 1.80 & inform & 1.89 & protect & 2.16 & act & 4.53 & direct & 1.27 \\
\hline secur & 1.78 & googl & 1.84 & compani & 1.88 & user & 4.20 & servic & 1.20 \\
\hline protect & 1.73 & person & 1.69 & act & 1.85 & data protect & 3.80 & includ & 1.13 \\
\hline personal data & 1.54 & facebook & 1.58 & malaysia & 1.64 & data us & 3.60 & multimedia & 1.13 \\
\hline year & 1.45 & privaci & 1.54 & year & 1.57 & process & 3.13 & $\mathrm{abu}$ & 1.07 \\
\hline govern & 1.30 & protect & 1.36 & secur & 1.55 & personal data protect & 3.00 & abu hassan & 1.07 \\
\hline googl & 1.25 & year & 1.34 & govern & 1.45 & shaberi & 2.73 & ahmad_shabery_said & 1.07 \\
\hline privaci & 1.23 & govern & 1.22 & us & 1.28 & consum & 2.53 & data_protection_act & 1.07 \\
\hline facebook & 1.19 & servic & 1.16 & data protect & 1.27 & inform & 2.20 & hassan & 1.07 \\
\hline servic & 1.18 & internet & 1.12 & peopl & 1.27 & commun & 2.13 & institut & 1.07 \\
\hline peopl & 1.11 & state & 1.11 & user & 1.21 & registr & 2.07 & organis & 1.07 \\
\hline us & 1.11 & peopl & 1.04 & servic & 1.21 & year & 2.07 & personal_data_protection_act & 1.07 \\
\hline law & 1.03 & includ & 1.03 & law & 1.07 & ahmad & 2.00 & protection_act & 1.07 \\
\hline \multirow[t]{8}{*}{ state } & 1.00 & us & 1.03 & bank & 1.06 & ahmad_shaberi & 2.00 & commission & 1.00 \\
\hline & & law & 1.00 & Busi & 1.05 & regist ${ }^{-}$ & 1.87 & data_commerci & 1.00 \\
\hline & & & & & & depart & 1.73 & data_protection_depart & 1.00 \\
\hline & & & & & & countri & 1.53 & insur & 1.00 \\
\hline & & & & & & malaysia & 1.53 & personal_data_commerci & 1.00 \\
\hline & & & & & & sector & 1.53 & personal_data_protection_depart & 1.00 \\
\hline & & & & & & commerci & 1.47 & protection_depart & 1.00 \\
\hline & & & & & & ministri & 1.40 & & \\
\hline
\end{tabular}

$(*)$ Due to space constraint, this table only shows words having an 'e'equal to or higher than 1 


\section{Discussion and Implications}

Our study examines how the Malaysian newspapers frame the PDPA news. The results unveil several interesting points. First, from the visibility analysis (Section 4.1) we found that Borneo Post achieved the highest frequency in referenced to the PDPA (i.e., counted by the number of months at which the related news were being reported); whereas The Sun Daily and The Star covered the PDPA news across the longest continuous period (10 months). However, The Sun Daily has printed copies only in the peninsula area, while The Star represents only $22 \%$ of all English newspapers in the country. In contrast, Malaysia Kini, New Sabah Times, and The Edge Markets were among those with the lowest effort in PDPA diffusion. From a further inspection of the results, we found that all newspapers had more PDPA-articles after its enforcement than before its enforcement. An exception was The Malaysian Insider which had consistent coverage before and after the enforcement. However, this newspaper was blocked by the Malaysian government in February 2016. In short, the PDPA has not received the attention it deserves from the newspapers especially considering its potential impact on the citizen's privacy and security issues. This is evident from the small number of news coverage given to the PDPA. Weighting the increasing importance of the PDPA in today's Internet era, the newspapers should have played more prominent role in disseminating the PDPA news.

Second, the number of headlines covering the PDPA news followed a similar pattern as the number of articles covering the topic. The number of headlines increased significantly after the enforcement of the PDPA. This suggests that frequent official events addressing the PDPA are needed to maintain this topic in the spotlight of newspapers. Considering that headlines are meant to give importance to news (Scheufele \& Tewksbury, 2007; Eveland et al., 2004), we can also conclude that the PDPA has not received the attention it deserves from the local newspapers.

Third, the newspapers position the articles in the category they see most fit. However, such positioning may not always maximize public attention. In our study, the PDPA news appear most frequently in the Technology section (classified as 'General' news). In fact, technology advancement and data in its digital form are closely linked together. The advancement of information technology has greatly increased the volume of digital data. It also smoothens the ease of data sharing and transferring while introducing the threats of security and privacy issues such as data stealing, hacking, and leaking. Since the PDPA addresses issues related to the treatment, use, and sharing of personal data, it is logical that news related to the PDPA are placed in the Technology section to draw the attention of concerned readers.

However, since the PDPA is a government policy that will influence the public, news on the PDPA should be categorized as 'Hard' and should be reported as soon as possible in the main section of the newspapers. Addressing the PDPA news in the Technology section limits the readership to those who are interested in technology only. Those who do not read the Technology category will not gain knowledge about the PDPA. To gain wider readership, newspapers should be more balanced in placing the PDPA news across different categories. Alternatively, newspapers could place the PDPA news in the sections most read by the majority of the readers, for instance, the World or Nation sections. By doing so, news on important government policies will reach a wider group of readers. However, the results show that these sections (World with 160 articles and Nation with 148 articles) covered only as much as $60 \%$ of the number of articles in the Technology section (261 articles). Moreover, with exception of the category Nation, The Star and the Malaysian Insider led the count of the number of PDPA articles in each category. Even for the category Nation, the difference between The Star that ranked second with 37 articles and Borneo Post that led the category with 39 articles is only 2 articles.

Fourth, the government has not actively pushed the PDPA agenda. We derive this conclusion from the small number of the PDPA news originating from Putrajaya. It is surprising to find that foreign sources reported the largest number of the PDPA news even though the PDPA is a Malaysia-owned policy. By right, local sources and the Malaysia government should have been the main distributors of this policy. Moreover, we found that before the enforcement of the PDPA, the Putrajaya government was not engaged in the diffusion of the policy. Other local and foreign sources also addressed this 
topic more after the enforcement than before the enforcement. We argue that our findings could be a reflection of Malaysians' attitude toward privacy issues.

The Malaysian Insider and The Star newspapers had the highest number of PDPA articles from foreign sources, while The Star and Borneo Post had highest number of PDPA articles from local sources. This finding, together with those from the visibility and position analysis, suggests that in general, readers of the Star, the Malaysian Insider, and Borneo Post had greater exposure to the PDPA news. Although it is important to mention that The Star represents only $22 \%$ of all English newspapers in the country, The Malaysian Insider was blocked in February 2016 and Borneo Post has print copies only for East Malaysia. In summary, this finding suggests that Putrajaya is not giving the PDPA policy the attention it deserves, which may be a problem because Putrajaya is the most trustworthy source on these issues and by right should play its role accordingly.

Fifth, from the analysis of the keywords, we found that although Putrajaya has the fewest articles on the PDPA, it has the highest exposure of PDPA-related keywords. A potential explanation is that the articles from the Putrajaya government were more focused than other sources and tended to use fewer words in the news. This translates into high degrees of exposure. As for foreign sources, the exposure of words such as Google and Facebook suggests that this source is influenced by the Internet and privacy threats. However, no word has a degree of exposure high enough (i.e., equal to or higher than 6) to sufficiently emphasize the importance of the PDPA. Undoubtedly, the volume of articles from foreign sources (480 out of 793 total articles) highly influences the degree of word exposure. Keywords such as 'rights' and 'principles' were barely mentioned across the three sources (with a degree of exposure less than 1). Considering that knowledge acquisition occurs through repetition, these results suggest that no article gives the readers enough exposure on the principles of the PDPA and their rights as protected by this Act.

Finally, our findings suggest the public has low awareness of the PDPA. To confirm this hypothesis, we conducted a follow-up survey of 421 random Malaysians who read newspapers and asked if they are aware of the PDPA. We found that only $36 \%$ of respondents were aware of the PDPA, and from these respondents only $43 \%$ obtained their knowledge about the PDPA from newspapers. Clearly, the newspapers have not been successful in disseminating news on the PDPA. This finding is echoed by Raus et al. (2014) and Hashim et al. (2013) that studied the awareness of the PDPA among youth and university students.

\subsection{Implications}

Our study has implications for the government's strategy in raising public awareness when introducing and enforcing new policies. The literature (Murukutla et al. 2011; Huang et al. 2015) has emphasized the role of media in bringing attention to new policies. While not directly linked, our findings on the lack of emphasis given by the newspapers to the PDPA and the findings of the followup survey on the lack of public awareness toward the PDPA suggest that newspapers could have played more visible role in reporting the PDPA news. In fact, according to Development Media Theory (Folarin, 1998; McQuail, 1994), media such as the newspapers should carry out positive development tasks in line with nationally established policies. The government, therefore, should work closely with the media (hence the newspapers in our study) to strategically advance public dialogs on government policies. In the case of the PDPA, for example, the government could educate the citizens via more informational articles published in newspapers. Accordingly, it is important that Putrajaya takes a more active role in disseminating this news since it is the most trustworthy source on the topic.

Another important finding is that the number of articles and headlines covering PDPA-related news increased after the enforcement of the PDPA. This suggests that the government should periodically address topics related to the PDPA which will keep the news at the spotlight of newspapers. This strategy may increase the number of articles and headlines as well as the period of time covered by media, which may increase the citizens' knowledge on the PDPA. 
Our findings also have implications for the media. In particular, how newspapers position the news will affect the readership. If the newspapers want higher attention, they could position the PDPA news on the main headlines, front page, and 'Hard' sections (e.g., World and Nation). They could also repeatedly report PDPA news or run special issues and discussions on the topic to generate more interest. It is also important that the media frames PDPA-related news with keywords that have great exposure because constant repetition significantly contributes to information retention. As the source with the highest exposure of keywords, it may be a good strategy for Putrajaya to set the guidelines for news on the PDPA.

\subsection{Limitations and Future Research}

Our study has some limitations that should be taken into account. First, we covered only English newspapers which confine our understanding to the presentation by the media of this one lingual. Future research could examine newspapers in other languages such as Mandarin and Malay and compare how newspapers of different languages differ in their presentation of the PDPA news. Would certain lingual, which may indirectly represent the people of different ethnic groups in Malaysia, place different weight on the PDPA, and hence the issue of privacy. Second, we included only ten newspapers that have digital formats, thus excluding those that exist only in hardcopies. We did so to obtain more complete archived news. Furthermore, with the latest media trend, most newspapers with wide readership are bound to have online digital copies. Since these ten newspapers have wide readership, they provide a good representation of how the media presents the PDPA news.

There are also potential avenues for other future research. First, research could investigate how various factors such as article positioning in a newspaper, the frequency at which a particular news appears in papers, and the category in which a news appears, affect readers' awareness. Second, research could examine how different media can be used to effectively disseminate information on government policies and regulations to the public.

\section{Conclusion}

The Internet age has significantly increased the exchange and flow of digital data, which raises concerns for privacy and data security. To govern the collection and use of data, governments across different parts of the world, including Malaysia, are enacting data protection policies and regulations. While the governments have good intention to protect the citizens by enacting the policies, they need to ensure the public are aware of such policies and their rights. To that end, media such as newspapers should play positive and significant role in disseminating information on government policies to the citizens. In fact, the media could and should help to raise awareness toward government policies in the citizens. However, our study shows that the media in Malaysia did not pay enough attention to PDPA issues.

Funding source

This work is supported by the Fundamental Research Grant Scheme (FRGS) from the Ministry of Education Malaysia (Grant Number: FRGS/1/2015/SS03/SYUC/02/1). 


\section{References}

Audit Bureau of Circulations Malaysia (2016). Latest Audit Reports - January to June 2016. http://abcm.org.my/reports/latest-audit-reports-january-to-june-2016/.

Baran, S. J. and Davis, D. K. (2009). Mass Communication Theory: Foundations, Ferment and Future. 5th Ed. Boston, USA: Wadsworth Cengage learning.

Bartels, L. M. (1996). September. Politicians and the Press: Who Leads, Who Follows? In APSA. San Francisco, CA.

Baum, M. A. (2003). 'Soft News and Political Knowledge: Evidence of Absence or Absence of Evidence?', Political Communication 20: 173-90.

Baumgartner, F. R., and Jones, B. D. (1993). Agendas and Instability in American Politics. Chicago: University of Chicago Press.

Bélanger, F., \& Crossler, R. E. (2011). Privacy in the digital age: a review of information privacy research in information systems. MIS quarterly, 35(4), 1017-1042.

Boykoff, M. (2005). The disconnect of news reporting from scientific evidence. Nieman Reports, 59(4), 86-87.

Caudill, E. M., \& Murphy, P. E. (2000). Consumer online privacy: Legal and ethical issues. Journal of Public Policy \& Marketing, 19(1), 7-19.

Cobb, R.W. and C.D Elder, C. D.(1972/1983). Participation in American Politics: The Dynamics of Agenda-Building Boston: Allyn and Bacon.

Cohen, B. C. (1963). The press and foreign policy. Princeton, NJ: Princeton University Press. De Vreese, C. H., Peter, J., \& Semetko, H. A. (2001). Framing politics at the launch of the Euro: A crossnational comparative study of frames in the news. Political Communication, 18, 107-122.

Conradie, P., \& Choenni, S. (2014). On the barriers for local government releasing open data. Government Information Quarterly, 31, S10-S17.

Curran, J., Iyengar, S., Lund, A. B., \& Salovaara-Moring, I. (2009). Media System, Public Knowledge and Democracy A Comparative Study. European Journal of Communication, 24(1), 5-26.

De Vreese, C. H. (2005). News framing: Theory and typology. Information design journal+ document design, 13(1), 51-62.

Dinev, T., \& Hart, P. (2005). Internet privacy concerns and social awareness as determinants of intention to transact. International Journal of Electronic Commerce, 10(2), 7-29.

Ecker, U. K., Lewandowsky, S., Chang, E. P., \& Pillai, R. (2014). The effects of subtle misinformation in news headlines. Journal of experimental psychology: applied, 20(4), 323.

Entman, R. M. (2004). Projections of power: Framing news, public opinion, and US foreign policy. University of Chicago Press.

Eveland, W. P., Jr., Marton, K. and Seo, M. (2004). 'Moving beyond "Just the Facts": The Influence of Online News on the Content and Structure of Public Affairs Knowledge'. Communication Research, 31(1), 82-108.

Fan, W., Wallace, L., Rich, S., \& Zhang, Z. (2006). Tapping the power of text mining. Communications of the ACM, 49(9), 76-82. 
Farnsworth, S. J., \& Lichter, S. R. (2006).The Mediated Presidency: Television News and Presidential Governance. Lanham, Md.: Rowman and Littlefield.

Farnsworth, S. J., \& Lichter, S. R. (2011). The Nightly News Nightmare: Media Coverage of U.S. Presidential Elections, 1988-2008. Lanham, MD: Rowman and Littlefield. Third Edition.

Flickinger, R. (1983). The comparative politics of agenda setting: The emergence of consumer protection as a public policy issue in Britain and the United States. Review of Policy Research, 2(3), 429-444.

Folarin, B. (1998). Theories of mass communication: An introductory text. Ibadan: Stirling-Horden Publishers.

Gamson, W. A., \& Modigliani, A. (1987). The changing culture of affirmative action. In R. G. Braungart \& M. M. Braungart (Eds.), Research in political sociology (Vol. 3, pp. 137-177). Greenwich, CT: JAI Press.

Grabe, M. E., Zhou, S., \& Barnett, B. (2001). Explicating sensationalism in television news: Content and the bells and whistles of form. Journal of Broadcasting \& Electronic Media, 45(4), 635-655.

Happer, C., \& Philo, G. (2013). The role of the media in the construction of public belief and social change. Journal of Social and Political Psychology, 1, 321-336.

Hashim, K. F., Ammar Rashid \& Shafiz Affendi Mohd Yusof (2013). Online Privacy Awareness using Social Media: A Case Study of Malaysian Youth. Information Systems International Conference (ISICO), 2-4 December 2013.

Hayes, D., \& Lawless, J. L. (2015). As Local News Goes, So Goes Citizen Engagement: Media, Knowledge, and Participation in US House Elections. The Journal of Politics, 77(2), 447-462.

Horst, M., Cobb, T., Cobb, T., \& Meara, P. (1998). Beyond A Clockwork Orange: Acquiring Second Language Vocabulary through Reading. Reading in a foreign language, 11(2), 207-223.

Huang, T. T., Cawley, J. H., Ashe, M., Costa, S. A., Frerichs, L. M., Zwicker, L. \& Kumanyika, S. K. (2015). Mobilisation of public support for policy actions to prevent obesity. The Lancet, 385(9985), 2422-2431.

Iyengar, Shanto, and Donald R. Kinder. 1987. News That Matters. Chicago: University of Chicago Press.

Iyengar, S., \& Simon, A. (1993). News Coverage of the Gulf Crisis and Public Opinion A Study of Agenda-Setting, Priming, and Framing. Communication Research, 20(3), 365-383.

Janssen, M., \& van den Hoven, J. (2015). Big and Open Linked Data (BOLD) in government: A challenge to transparency and privacy?. Government Information Quarterly, 32(4), 363-368

Kassen, M. (2013). A promising phenomenon of open data: A case study of the Chicago open data project. Government Information Quarterly, 30(4), 508-513.

Kingdon, J. (1984). Agenda-Setting, Alternatives and Public Policies. New York: Harper Collins.

Larson, S. G. (2001). Poll coverage of the 2000 presidential campaign on the network news. In annual meeting of the American Political Science Association, San Francisco.

Lehman-Wilzig, S. N., \& Seletzky, M. (2010). Hard news, soft news, 'general'news: The necessity and utility of an intermediate classification. Journalism, 11(1), 37-56. 
Leighley, J. E. (2003). Mass Media and Politics: A Social Science Perspective. Houghton Mifflin Harcourt Publishing Company.

Libaque-Saenz, C. F., Chang, Y., Kim, J., Park, M. C., \& Rho, J. J. (2016). The role of perceived information practices on consumers' intention to authorise secondary use of personal data. Behaviour \& Information Technology, 35(5), 339-356.

Limor, Y., \& Mann, R. (1997). Itona’ut. Journalism. Tel Aviv: Open University.

Liu, C., \& Arnett, K. P. (2002). An examination of privacy policies in Fortune $500 \mathrm{Web}$ sites. American Journal of Business, 17(1), 13-22.

Mayer, R. N. (1991). Gone Yesterday, Here Today: Consumer Issues in the Agenda - Setting Process. Journal of Social Issues, 47(1), 21-39.

McCombs, M. (2004). Setting the Agenda: The Mass Media and Public Opinion. Malden, MA: Blackwell Publishing Inc.

McCombs, M., \& Shaw, D. L. (1972). The Agenda-Setting Function of Mass Media. Public Opinion Quarterly, 36(2), 176-187. doi:10.1086/267990.

McQuail, D. (1994). Mass Communication Theory: An Introduction. 3 ed. Thousand Oaks, CA: Sage.

Mooney, C. (2004). Blinded by science: How 'balanced' coverage lets the scientific fringe hijack reality. Columbia Journalism Review, 6, November/December.

Moores, T. (2005). Do consumers understand the role of privacy seals in e-commerce?.

Communications of the ACM, 48(3), 86-91.

Murukutla, N., Turk, T., Prasad, C. V. S., Saradhi, R., Kaur, J., Gupta, S.\& Wakefield, M. (2011).

Results of a national mass media campaign in India to warn against the dangers of smokeless tobacco consumption. Tobacco Control, tc-2010, Published Online First: 20 April 2011

doi:10.1136/tc.2010.039438.

PDPA (2010). Laws of Malaysia, Act 709, Personal Data Protection Act 2010.

Patterson, T. E. (2000). Doing Well and Doing Good: How Soft News and Critical Journalism are Shrinking the News Audience and Weakening Democracy - and What News Outlets Can Do about It. Faculty Research Working Paper Series, RWP01-001. Cambridge, MA: John F. Kennedy School of Government, Harvard University.

Peterson, S.A. (2014). The Effect of Social Media on Public Awareness and Extra-Judicial Effects: The Gay Marriage Cases and Litigating for New Rights.

Prior M (2003). Any good news in soft news? The impact of soft news preference on political knowledge. Political Communication 20(2): 149-171.

Pritchard, D. (1986). Homicide and bargained justice: The agenda-setting effect of crime news on prosecutors. Public Opinion Quarterly, 50(2), 143-159.

Raus, MIM, Tah, IHM \& S Yahya (2014). Awareness on Legal Rights and Data Protection in SNS: The Case of Facebook in Countryside Campus. Proceedings of the International Conference on Science, Technology and Social Sciences (ICSTSS), pp. 161-169.

Rott, S. (1999). The effect of exposure frequency on intermediate language learners' incidental vocabulary acquisition and retention through reading. Studies in Second Language Acquisition, 21(04), 589-619. 
Santos, C. K.; Evsukoff, A. G.; Lima, B.S.L.P. (2008). Cluster analysis in document networks. WIT Transactions on Information and Communication Technologies, v. 40, pp. 95-104. 2008.

Saragi, T., Nation, I. S. P., \& Meister, G. F. (1978). Vocabulary learning and reading. System, 6(2), $72-78$

Scheufele, D. A., \& Tewksbury, D. (2007). Framing, Agenda Setting, and Priming: The Evolution of Three Media Effects Models. Journal of Communication, 57(1), 9-20. doi:10.1111/j.14602466.2006.00326.x

Schmitt, N., \& McCarthy, M. (Eds.). (1997). Vocabulary: Description, acquisition and pedagogy (Vol. 2035). Cambridge: Cambridge university press.

Schwaig, K. S., Kane, G. C., \& Storey, V. C. (2006). Compliance to the fair information practices: How are the Fortune 500 handling online privacy disclosures? Information \& management, 43(7), 805-820.

Siegel + Gale (2012). Survey Finds Facebook and Google Privacy Policies Even More Confusing Than Credit Card Bills and Government Notices, http://www.prnewswire.com/news-releases/survey-findsfacebook-and-google-privacy-policies-even-more-confusing-than-credit-card-bills-and-governmentnotices-148653725.html.

Smith, F. L. (1985). Perspectives on Radio and Television: Telecommunication in the United States. New York: Harper \& Row.

Smith, H. J., Dinev, T., \& Xu, H. (2011). Information privacy research: an interdisciplinary review. MIS quarterly, 35(4), 989-1016.

Tewksbury, D., \& Althaus, S. L. (2000). Differences in knowledge acquisition among readers of the paper and online versions of a national newspaper. Journalism \& Mass Communication Quarterly, $77(3), 457-479$.

Tewksbury, D., Weaver, A. J., \& Maddex, B. D. (2001). Accidentally Informed: Incidental News Exposure on the World Wide Web. Journalism \& Mass Communication Quarterly, 78(3), 533-554.

Thestar (2015). The Star still M'sia's preferred.

http://www.thestar.com.my/news/nation/2015/03/28/the-star-still-msias-preferred-english-dailyreadership-increased-by-74-says-survey/

Tuchman, G. (1973). Making news by doing work: Routinizing the unexpected. American journal of Sociology, 79(1), 110-131.

Waring, R., \& Takaki, M. (2003). At what rate do learners learn and retain new vocabulary from reading a graded reader. Reading in a Foreign language, 15(2), 130-163.

Webb, S. (2007). The effects of repetition on vocabulary knowledge. Applied linguistics, 28(1), 4665 .

Whetmore, E. J. (1989). Mediamerica: Form, content, and consequence of mass communication. Wadsworth Publishing Company, Belmont, CA: Wadsworth.

Yanovitzky, I. (2002). Effects of news coverage on policy attention and actions: A closer look into the media-policy connection. Communication research, 29(4), 422-451.

Zuiderwijk, A., \& Janssen, M. (2014). Open data policies, their implementation and impact: A framework for comparison. Government Information Quarterly, 31(1), 17-29. 